\title{
HCG stimulation test in children with abnormal sexual development
}

\author{
D. B. GRANT, BERNARD M. LAURANCE, SHELIA M. ATHERDEN, and JENNIFER RYNESS \\ From The Hospital for Sick Children and Institute of Child Health, London, and Queen Elizabeth Hospital \\ for Children, Hackney
}

\begin{abstract}
Grant, D. B., Laurance, B. M., Atherden, S. M., and Ryness, J. (1976). Archives of Disease in Childhood, 51, 596. HCG stimulation test in children with abnormal sexual development. Plasma testosterone was estimated by radioimmunoassay in 60 children with disorders of sexual development before and after stimulation with human chorionic gonadotrophin (HCG). In 21 children the testosterone levels after 3 and 5 daily injections of 1000 units HCG were compared and good correlation was found between the paired results $(r=0.93)$, suggesting that the 5-day HCG test has no advantage over the 3-day test. In 7 boys with apparently normal genital development the increments in plasma testosterone ranged from 2.0 to $8.5 \mathrm{nmol} / 1$ after 3 injections of HCG. 10 boys with anorchia showed little response to HCG stimulation, but in patients with other disorders, such as micropenis (10), cryptorchidism (8), hermaphroditism (3), male pseudohermaphroditism (13), hypospadias (3), and sex chromosome anomalies (6), there was considerable variation in the plasma testosterone level after HCG. In 2 boys with suspected anorchia the results suggested that testes were present and this was confirmed at operation.
\end{abstract}

With increasing availability of suitable radioimmunoassay methods estimation of plasma testosterone is becoming more widely used to evaluate testicular endocrine function. As there is relatively little spontaneous secretion of testosterone in young boys after the first few weeks of life (Forest et al., 1974), stimulation of Leydig-cell activity with gonadotrophins is necessary when investigating prepubertal subjects. There are already a number of reports on the use of the human chorionic gonadotrophin (HCG) stimulation test in boys with anorchia (Rivarola, Bergada, and Cullen, 1970; Levine and New, 1971; Rudd et al., 1973; Cacciari et al., 1974). The test has also been used to investigate boys with cryptorchidism or delayed puberty (Attanasio et al., 1974; Canlorbe et al., 1974; Cacciari et al., 1974; Rudd et al., 1973), and to study testicular function in subjects with hermaphroditism or sex chromosome anomalies (Rivarola et al., 1970; Saez, Frédérich, and Bertrand, 1971; Neto et al., 1973). However, in these latter groups of patients the clinical value of the test is still uncertain. This paper describes plasma testo-

Received 22 December 1975. sterone (which includes $5 \alpha$-dihydrotestosterone) before and after HCG in 60 patients with various abnormalities of genital development, and attempts to analyse the clinical value of the findings.

\section{Patients}

The 60 subjects have been divided into 8 groups on clinical grounds. Details of their diagnoses and ages are summarized in the Table. Only 6 showed pubic hair (stage II) at the time of investigation.

I. Apparently normal genital development. HCG tests were performed in 3 boys with delayed puberty, 3 boys in whom a normally-formed penis was buried in subcutaneous fat, and 1 boy with unexplained gynaecomastia. All showed a normal male pattern on buccal smear or chromosome analysis and infantile testes were present in the scrotum.

II. Anorchia. 10 boys in whom testes could not be found at operation were investigated after surgical exploration. All had a normally formed penis and in half remnants of vas deferens could be identified in one or both groins at operation. Chromosome analysis or buccal smear was performed in 6 and showed a male pattern. 
TABLE

Clinical details in 60 patients

\begin{tabular}{|c|c|c|c|c|}
\hline Group & Diagnosis & $\mathbf{n}$ & $\begin{array}{c}\text { Age (yr) } \\
\text { (mean \& range) }\end{array}$ & $\begin{array}{l}\text { Increment in plasma } \\
\text { testosterone (nmol/l) } \\
\text { after } 3 \text { injections } \\
\text { of HCG } \\
\text { (mean \& range) }\end{array}$ \\
\hline I & Apparently normal & 7 & $\begin{array}{c}11 \cdot 4 \\
(8 \cdot 6-13 \cdot 2)\end{array}$ & $\begin{array}{c}5 \cdot 2 \\
(2 \cdot 0-8 \cdot 5)\end{array}$ \\
\hline II & Anorchia & 10 & $12 \cdot 6$ & $\begin{array}{c}0.2 \\
(0-0.5)\end{array}$ \\
\hline III & Cryptorchid & 8 & $\begin{array}{c}11 \cdot 9 \\
(7 \cdot 9-15 \cdot 7)\end{array}$ & $\begin{array}{c}5 \cdot 8^{\star} \\
(0 \cdot 8-18 \cdot 2)\end{array}$ \\
\hline IV & Micropenis & 10 & $7 \cdot 3$ & $1 \cdot 7$ \\
\hline $\mathbf{v}$ & $\begin{array}{l}\text { Male pseudo- } \\
\text { hermaphrodite }\end{array}$ & 13 & $\begin{array}{c}7 \cdot 9 \\
(0 \cdot 1-16 \cdot 2)\end{array}$ & $\begin{array}{c}6.9 \\
(0.5-14.9)\end{array}$ \\
\hline VI & Hypospadias & 3 & $3 \cdot 0$ & $3 \cdot 8$ \\
\hline VII & Hermaphrodite & 3 & $7 \cdot 1$ & $8 \cdot 2$ \\
\hline VIII & $\begin{array}{l}\text { Sex chromosome } \\
\text { anomaly }\end{array}$ & 6 & $\begin{array}{c}(0 \cdot 1-10 \cdot 9) \\
7 \cdot 5 \\
(0 \cdot 2-13 \cdot 9)\end{array}$ & $\begin{array}{c}(2 \cdot 0-18 \cdot 4) \\
3 \cdot 1 \\
(0 \cdot 8-8 \cdot 3)\end{array}$ \\
\hline
\end{tabular}

*A sample was not obtained after 3 injections in 1 boy.

III. Cryptorchid/hidden testes. 8 boys with bilateral undescended testes were studied. 7 had had previous surgical exploration, and in 5 the testes had either appeared abnormally small or could not be fully mobilized. In 2, testes were not found at the first operation. Re-exploration was carried out when the results of the HCG test were known and both were found to have intra-abdominal testes which could not be fully mobilized.

IV. Micropenis with undescended testes. 10 males with marked penile hypoplasia, undescended testes, and underdevelopment of the scrotum were investigated. In 2 surgery had not been carried out but in the remainder the testes appeared abnormally small or absent at operation. Chromosome analysis was carried out in 7 of these patients and showed a male karyotype. In 3 patients no erectile tissue could be felt in the penis and it was considered more appropriate to raise them as girls.

v. Male pseudohermaphrodites. HCG tests were carried out in 13 patients with a male karyotype associated with severe scrotal hypospadias, a variable degree of chorde, and bifid scrotum. 2 patients had small intra-abdominal testes and in one of these a small uterus was present; in the remainder, testes were palpable in the scrotal folds and no Müllerian derivatives were found at operation. There were 2 pairs of brothers in this group and in one of these families the mother had a third affected child on remarriage, suggesting $\mathrm{X}$-linked inheritance. 3 of the patients in this group had been raised as girls.

VI. Penile hypospadias. 3 boys with penile hypospadias and a normal scrotum were studied. Small inguinal testes were found in one but the others had apparently normal scrotal testes.

VII. Hermaphrodites. 3 children with both an ovary and a testis were investigated. Chromosome studies carried out on 2 of these children showed a male karyotype.

VII. Sex chromosome anomalies. HCG tests were performed in 2 patients with mixed gonadal dysgenesis (XO/XY), 2 patients with bilateral testes and an XX karyotype, and 2 patients with $X X Y$ and $X X X X Y$ karyotypes, respectively.

\section{Methods}

Stimulation tests were carried out by giving 1000 units HCG (Organon; Paines and Byrne) by intramuscular injection for 3 consecutive days, usually on an outpatient basis. Venous samples were taken before and approximately 24 hours after the 3rd HCG injection. In 22 patients 2 further injections of HCG were given and another sample collected on the 6th day about 24 hours after the last dose of HCG.

Plasma testosterone was estimated by radioimmunoassay, using antiserum raised against testosterone-3oxime bovine serum albumin conjugate. This antiserum showed $76 \%$ cross-reaction with $5 \alpha$-dihydrotestosterone, but negligible cross-reaction with $\Delta$ 4-androstenedione, $\Delta$ 5-androstenediol, dehydroepiandrosterone, or $17 \alpha$-hydroxyprogesterone. Plasma samples $(50-250 \mu 1)$ were extracted with $2.5 \mathrm{ml}$ hexane : ether $(4: 1 \mathrm{v} / \mathrm{v})$ and $1.0 \mathrm{ml}$ aliquots of extract taken for assay. ${ }^{3} \mathrm{H}$-testosterone (5000 dpm) was added before evaporation of the extracts to dryness and overnight incubation at $4^{\circ} \mathrm{C}$ with $0.25 \mathrm{ml}$ antibody diluted 
Male Pseudo- Hermaphrodite • hermaphrodite $\bullet$ Sex-chromosome Hypospadias $0 \quad$ Anomaly $\circ$
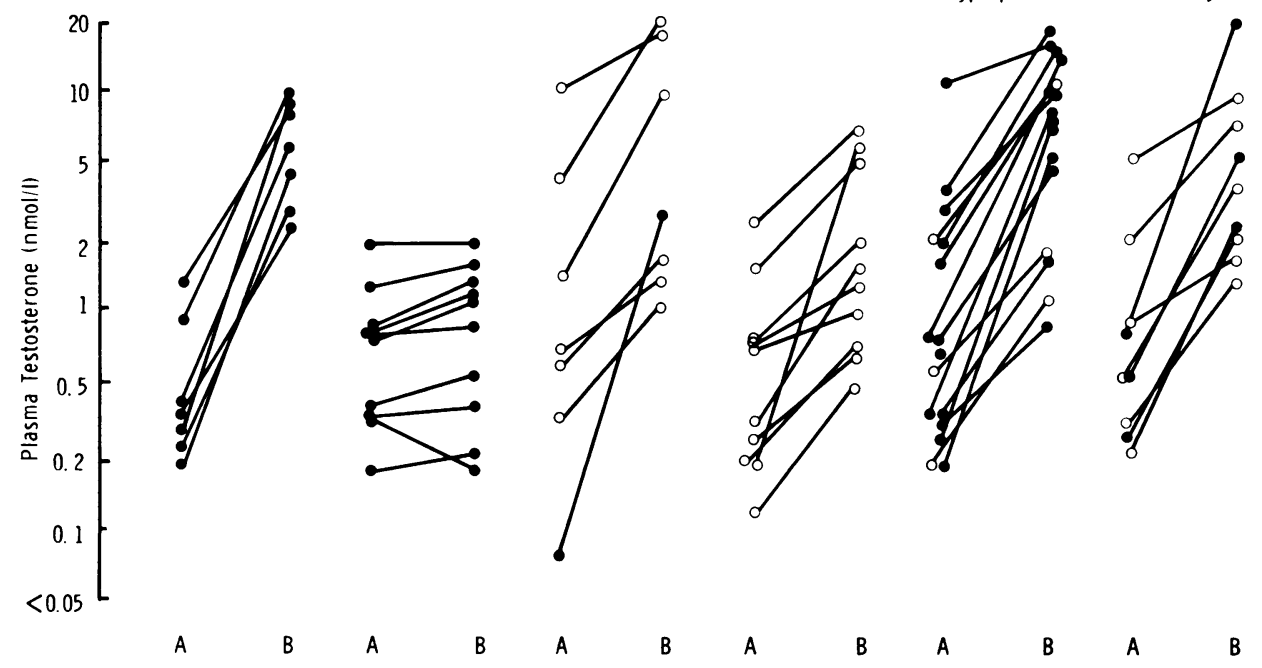

FIG. 1.-Plasma testosterone levels in 59 patients before $(A)$ and after $(B) 3$ injections of human chorionic gonadotrophin.

$1: 50000$ in $0.1 \mathrm{~mol} / 1$ borate buffer $(p \mathrm{H} 8 \cdot 0)$ with $0.06 \%$ bovine serum albumin and $0.05 \%$ human $\boldsymbol{\gamma}$-globulin. Bound and free hormone were separated by ammonium sulphate precipitation and centrifugation before aliquots of supernatant were taken for counting.

Recovery of unlabelled testosterone over the range $0.03-0.28$ pmol was $99.5 \%$ (range $88-120 \%$ ) and the interassay variation for 2 control samples with mean values of $12 \cdot 5$ and $16 \cdot 8 \mathrm{nmol} / 1$ were $7 \cdot 5 \%$ and $6 \cdot 2 \%$, respectively. Using this assay, the mean plasma testosterone level in 10 men was $14 \cdot 7 \mathrm{nmol} / 1$ (range $10 \cdot 8-22 \cdot 5 \mathrm{nmol} / \mathrm{l})$.

\section{Results}

The average increments in plasma testosterone after 3 injections of HCG are given in the Table and the responses of individual patients are shown in Fig. 1. The increments in plasma testosterone after 3 and 5 doses of HCG are compared in Fig. 2.

I. Normal genitalia. On average the 7 boys in this group showed a 13-fold rise in plasma testosterone after 3 days HCG, with increments in plasma testosterone between 2.0 and $8.5 \mathrm{nmol} / 1$ and peak values between $2 \cdot 3$ and $8 \cdot 7 \mathrm{nmol} / \mathrm{l}$.

II. Anorchia. Basal testosterone levels up to $1.9 \mathrm{nmol} / 1$ were obtained in the boys with anorchia. Half the patients showed a slight rise in testosterone after HCG but this was never more than $50 \%$ of the basal value.
III. Cryptorchid/hidden testes. Six cryptorchid boys showed a 2- to 8-fold rise in plasma testosterone after 3 injections of HCG but there was

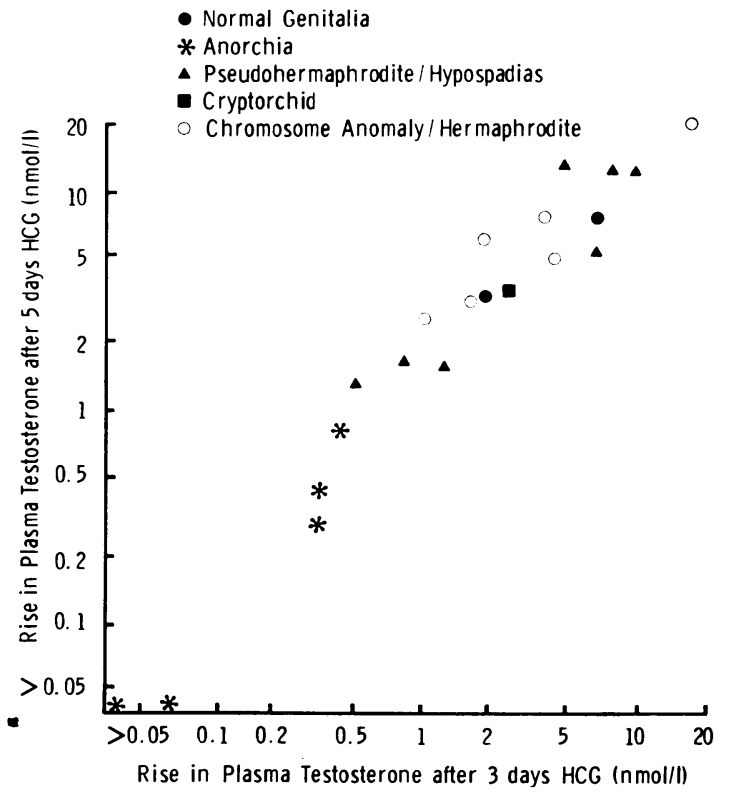

FIG. 2.-Increments in plasma testosterone after 3 and 5 injections of human chorionic gonadotrophin (HCG) in 21 patients. 
considerable variation in the peak values obtained. In 3 the levels were below $1.7 \mathrm{nmol} / \mathrm{l}$, and in 3 they were greater than $9 \cdot 7 \mathrm{nmol} / \mathrm{l}$. There was no obvious correlation between the testosterone responses and the appearance of the testes at previous operation.

Both boys with suspected anorchia showed a good response to HCG. In one, the plasma testosterone rose from $1.4 \mathrm{nmol} / 1$ to $15.3 \mathrm{nmol} / 1$ after 5 injections of HCG. A sample was not obtained after 3 doses in this boy. In the other the level rose from 0.1 nmol/1 to $2.5 \mathrm{nmol} / \mathrm{l}$ after 3 days HCG. Intraabdominal testes were subsequently found in both these patients.

IV. Micropenis. All the patients with micropenis and undescended testes showed a rise in testosterone after 3 days HCG but again there was considerable variation in the response. In 7 the post-HCG values were less than $2.0 \mathrm{nmol} / 1$, while in 3 the levels were greater than $4.9 \mathrm{nmol} / \mathrm{l}$. There was no obvious correlation between the testosterone responses and the severity of penile hypoplasia and 2 of the 3 children raised as girls had post-HCG levels of 4.9 and $9.6 \mathrm{nmol} / 1$ respectively.

V. Male pseudohermaphroditism. The majority of the patients in this group had a good response to HCG with an 8-fold increase in plasma testosterone on average. With the exception of 2 children who had small intra-abdominal testes, the post-HCG levels were above $4 \cdot 4 \mathrm{nmol} / \mathrm{l}$.

VI. Hypospadias. 2 of the boys with penile hypospadias showed poor responses with peak levels of 1.0 and $1.7 \mathrm{nmol} / \mathrm{l}$, but in the third the testosterone rose from 1.8 to $11.0 \mathrm{nmol} / 1$.

VII. Hermaphrodites. All 3 patients responded to 3 injections of HCG with peak values between $2 \cdot 3$ and $19 \cdot 0 \mathrm{nmol} / \mathrm{l}$.

VII. Chromosome anomalies. The 2 children with mixed gonadal dysgenesis showed good responses to 3 days' HCG with peak values of 10.0 and $8.2 \mathrm{nmol} / \mathrm{l}$. Poorer responses were obtained in the 'XX males' with post-HCG values of 1.3 and $2.0 \mathrm{nmol} / 1$. The post-HCG levels in the XXY and XXXXY patients were 3.5 and 1.6 nmol/1, respectively.

Relationship between basal testosterone and response to HCG. In general the patients with the highest basal testosterone levels showed the highest levels after HCG. Analysis of the results for all the patients except those with anorchia showed a significant correlation between basal and post-HCG values $(r=0.51, P<0.01)$. A lesser correlation was found when the basal values were compared with the increments in testosterone level $(r=0.32, P<0 \cdot 05)$.

Relationship between results after 3 and 5 injections of HCG. Although greater increments in plasma testosterone were generally found after the longer period of stimulation (Fig. 2), there was good correlation between the paired results obtained in 21 patients after 3 and 5 injections of HCG $(r=0.93, P<0.001)$.

\section{Discussion}

It is now widely recognized that short-term administration of HCG produces a rise in plasma testosterone in prepubertal boys (Frasier, Gafford, and Horton, 1969; Rivarola et al., 1970) and it is apparent that this response increases progressively during puberty (Canlorbe et al., 1974). It is also clear that there is wide variation in the plasma testosterone response to HCG, even in normal subjects (Canlorbe et al., 1974; Cacciari et al., 1974), and as a result the interpretation of the findings in an individual patient may be difficult. The subjects in the present study showed a wide range of genital anomalies and only a few could be assumed to have normal testicular function. The results in these children, with peak levels between 2.3 and $8.7 \mathrm{nmol} / 1$, are similar to those obtained by Rudd et al. (1973) in a small group of boys with delayed puberty, and to those described by Cacciari et al. (1974) in 26 normal prepubertal children. In general they are somewhat lower than those reported by Saez et al. (1971) and Canlorbe et al. (1974) in normal boys after slightly longer periods of HCG stimulation.

Although our results do not permit conclusions on the full range of the plasma testosterone response to HCG which can be expected in normal boys, we believe that the findings do give some information on the value and limitations of the HCG test. At present its main use lies in confirming or refuting the diagnosis of anorchia. A number of results in boys with anorchia have already been published (Rivarola et al., 1970; Rudd et al., 1973; Cacciari et al., 1974) and the present study provides further evidence for its value in this situation. The anorchic patients described above showed little response to HCG, though basal testosterone levels were slightly raised in some of the older boys. 
We do not know whether these basal values reflect the activity of testicular remnants or whether the testosterone was adrenal in origin. Adrenal suppression with dexamethasone at the time of HCG stimulation might have clarified this point (Cacciari et al., 1974) but we do not believe that it would have added to the clinical value of the test. HCG stimulation has also been of value in detecting concealed intra-abdominal testes (Levine and New, 1971), and in 2 of our patients with suspected anorchia the results of the test led to re-exploration. Though testes were found in both boys, orchidopexy was not possible in either and as a result the test brought no direct benefit.

Several authors have reported that plasma testosterone responses to HCG are lower in cryptorchid subjects than in normal boys (Attanasio et al., 1974; Canlorbe et al., 1974; Cacciari et al., 1974) and our own results are in keeping with these findings. However, 3 patients had good testosterone increments, even though orchidopexy was not possible at earlier operation. We do not know whether the subjects with poor responses will show incomplete virilization at the time of puberty but we believe that some may require androgen therapy at a later date.

Bergada et al. (1962) have described 4 boys in whom penile hypoplasia was associated with small dysplastic intra-abdominal testes, and a negligible testosterone response to HCG was found in a similar case (Grant and Dillon, 1975). 10 such patients were investigated in the present study and the majority showed poor responses to HCG. However, in 3 the testosterone levels after HCG appeared to be in the normal range. Parks et al. (1974) obtained very smilar results in a male with rudimentary testes and female external genitalia and clearly these patients may not have complete failure of testosterone secretion, even though the testes may be barely recognizable at operation. While the genital anomaly in many of our patients can probably be attributed to impaired testosterone production during early fetal life, the results do not distinguish between gonadotrophin deficiency and primary testicular failure as possible causes of the penile hypoplasia, as some patients with gonadotrophin deficiency may show a subnormal response to short-term HCG stimulation (Boyar et al., 1973; Bardin et al., 1969).

Variable responses to HCG have been described in male pseudohermaphrodites (Saez et al., 1971; Neto et al., 1973). In the present investigation 2 boys with small intra-abdominal testes showed a poor response and we think that the cause of the genital anomaly in these patients may be similar to that which produces micrpenis. However, in the majority of the patients with pseudohermaphroditism, there was a good response to HCG and the results were in keeping with the apparently normal testes found at operation. In these patients the test was of little value in defining the cause of the genital anomaly and more sophisticated techniques are required to identify the nature of these disorders. For example, some patients may have had a defect of $5 \alpha$-reductase and as a result could not convert testosterone to its more active derivative, $5 \alpha-$ dihydrotestosterone (Imperato-McGinley et al., 1974). As the radioimmunoassay did not discriminate between these two androgens, the test could not be used to identify this disorder. Again, other defects of androgen biosynthesis, such as the $3 \beta$-dehydrogenase defect, may not be complete and HCG stimulation produces a rise in plasma testosterone (Rosenfield et al., 1974). Such conditions may only be identified if testosterone precursors are also studied. Alternatively, some of the patients may have had partial tissue-unresponsive ness to androgen and in such cases the response to HCG would be expected to be normal. In this situation an apparently normal secretion of testosterone might not be associated with full virilization at puberty.

All the patients with hermaphroditism or sex chromosome anomalies showed a rise in testosterone after HCG but, as in the other groups of patients, there was wide variation in the response. In some of these patients, there was doubt as to whether adequate virilization would occur at puberty. We believe that the good responses shown by some of them allowed an encouraging prognosis to be given for later development.

There has been considerable variation in the dosage and duration of HCG stimulation used by different groups. For example, the dose of HCG has varied from 800 units to 5000 units (Rivarola et al., 1970; Frasier et al., 1969) and the period of stimulation from 3 days to 6 weeks (Cacciari et al., 1974; Attanasio et al., 1974). The amount of HCG used in the present investigation was chosen arbitrarily but the results are similar to those obtained by others using larger doses (Rudd et al., 1973; Cacciari et al., 1974), and we believe that 1000 units HCG probably gives maximal stimulation. The results described above indicate that the 5-day test has no advantages over the 3-day test. Though we still do not know the full range of the response to 3 injections of HCG in normal boys, our results suggest that a post-HCG testosterone level below $2 \cdot 0 \mathrm{nmol} / 1$ may indicate impaired Leydig-cell function, particularly if there is only a 
small rise in testosterone after stimulation. However, we still have to wait until many of the subjects reach the age of puberty in order to evaluate our results fully.

We thank many colleagues for referring their patients and for helping to carry out the tests, and Professor $\mathrm{K}$. Griffiths of the Tenovus Institute for Cancer Research, Cardiff, for a gift of antitestosterone-3-BSA serum.

\section{REFERENCES}

Attanasio, A., Jendericke, K., Bierich, J. R., and Gupta, D. (1974) Clinical and hormonal effects of human chorionic gonadotrophin in prepubertal cryptorchid boys. Fournal of Endocrino$\log y, 63,50 \mathrm{P}$.

Bardin, C. W., Ross, G. T., Rifkind, A. B., Cargille, C. M, and Lipsett, M. B. (1969). Studies of the pituitary-Leydig cell axis in young men with hypogonadotropic hypogonadism and hyposmia. Fournal of Clinical Investigation, 48, 2046.

Bergada, C., Cleveland, W. W., Jones, H. W., Jr., and Wilkins, I. (1962). Variants of embryonic testicular dysgenesis: bilateral anorchia and the syndrome of rudimentary testes. Acta Endocrinologica, 40, 521.

Boyar, R. M., Finkelstein, J. W., Witkin, M., Kapen, S., Weitzman, E., and Hellman, L. (1973). Studies of endocrine function in 'isolated' gonadotrophin deficiency. Fournal of Clinical Endocrinology and Metabolism, 36, 64

Cacciari, E., Cicognani, A., Tassoni, P., Flamigni, P., Bolelli, F., Pirazzoli, P., and Salardi, S. (1974). Plasma testosterone and oestradiol concentration in prepubertal boys with cryptorchidism before and after dexamethasone and after human chorionic gonadotrophin administration. Helvetica Paediatrica Acta, 29, 27.

Canlorbe, P., Borniche, P., Bader, J.-C., Vassal, J., Toublanc, J.-E., and Job, J.-C. (1974). La cryptorchidie. Archives Francaises de Pédiatrie, 31, 145.

Forest, M. G., Sizonenko, P. C., Cathiard, A. M., and Bertrand, J. (1974). Hypophyso-gonadal function in humans during the first year of life: evidence for testicular activity in early infancy. fournal of Clinical Investigation, 53, 819.

Frasier, S. D. Gafford, F., and Horton, R. (1969). Plasma androgens in childhood and adolescence. Fournal of Clinical Endocrinology and Metabolism, 20, 1404.

Grant, D. B., and Dillon, M. J. (1975). Micropenis associated with testicular agenesis. Archives of Disease in Childhood, 50, 247.

Imperato-McGinley, J., Guerrero, L., Gautier, T., and Peterson, R. E. (1974). Steroid $5 \alpha$-reductase deficiency in man. Science, 186, 1213.

Levine, L. S., and New, M. I. (1971). Preoperative detection of hidden testes. American fournal of Diseases of Children, 121, 176.

Neto, R. S., Rivarola, M. A., Coco, R., and Bergada, C. (1973). The testis in patients with abnormalities of sex differentiation. Acta Endocrinological, 73, 179.

Parks: G. A., Dumars, K. W., Limbeck, G. A., Quinlivan, W. L., and New, M. I. (1974). 'True agonadism': a misnomer? Fournal of Pediatrics, 84, 375.

Rivarola, M. A., Bergada, C., and Cullen, M. (1970). HCG stimulation test in prepubertal boys with cryptorchidism, in bilateral anorchia and in male pseudohermaphroditism. Journal of Clinical Endocrinology and Metabolism, 31, 526.

Rosenfield, R. L., Barmach de Niepomniszsze, A., Kenny, F. M., and Genel, M. (1974). The response to human chorionic gonadotrophin administration in boys with and without $\Delta^{5}-3 \beta$-hydroxysteroid dehydrogenase deficiency. Fournal of Clinical Endocrinology and Metabolism, 39, 370.

Rudd, B. T., Rayner, P. H. W., Smith, M. R., Holder, G., Jivani, S. K. M., and Theodoris, C. G. (1973). Effect of human chorionic gonadotrophin on plasma and urine testosterone in boys with delayed puberty. Archives of Disease in Childhood, 48 590.

Saez, J. M., Frédérich, A., and Bertrand, J. (1971). Endocrine and metabolic studies in children with male pseudo-hermaphroditism. Fournal of Clinical Endocrinology and Metabolism, $32,611$.

Correspondence to Dr. D. B. Grant, The Hospital for Sick Children, Great Ormond Street, London WC1N 3JH. 